\title{
El Castell Vell de Castelló o el paradigma de la ocupación antrópica del territorio de La Plana hasta el siglo XIII
}

The Castelló's old castle (Castell Vell), or the paradigm of the anthropic territory's occupation in La Plana until the thirteenth century

\author{
Jaime Prior y Llombart a, Pablo García Borja ${ }^{\text {b }}$, Joan Enric Palmer Broch ${ }^{\text {, }}$ Fermin \\ Font Mezquita ${ }^{d}$ \\ ${ }^{a}$ Departamento de Proyectos Arquitectónicos - Escuela Técnica Superior de Arquitectura - Universitat Politècnica de \\ València, Valencia, Spain, prior@ctac.es \\ ${ }^{\mathrm{b}}$ Universidad Nacional de Educación a Distancia - Centro Alcira, Alcira (Valencia), Spain, pabgarcia@valencia.uned.es \\ ${ }^{c}$ Arqueólogo, Borriol (Castellón), Spain, tecleret@ hotmail.com \\ d Arquitecto Técnico, Vila Real (Castellón), Spain, ferminfont@ gmail.com
}

\begin{abstract}
The Castell Vell of Castelló (Castelló's Old Castle) is an andalusian structure located at the top on a hill, placed on northern region of La Plana, in the land of Castellón. It's organized on three interconnected platforms, as many andalusians castles: alcazaba, albacara and the village itself. With 1,1 hectares surface, it follows the pattern of "castle associated with a rural habitat" according the Bazzana's classification. Its conservation status advises a series of interventions, the last one dated in 2018.

Defensive structures have, in general, a high homogeneity in terms of construction techniques, but different moments and build phases can be identified. Its configuration is not uncommon in the almohad military structures of the Iberian land that can be dated between the twelfth and the thirteenth centuries. The presentation at this congress of this heritage piece and the description of the last intervention made is the objective of this study.
\end{abstract}

Keywords: Castle, andalusian, settlement, defense, alcazaba, albacara.

\section{Consideraciones generales}

El Castell Vell es un conjunto considerado monumento según anotación de fecha 15/11/1996 (Na R-I-51-0009255, al amparo de la Disposición Adicional $2^{\mathrm{a}} \mathrm{s}$ de la Ley 16/1985) asimilado a Bien de Interés Cultural según la vigente legislación de Patrimonio de la Comunidad Valenciana. Se sitúa en las coordenadas $40^{\circ} 02^{\prime} 06^{\prime \prime} \mathrm{N}$ 000'19'” y tiene una extensión de 1,1 hectáreas. Posee entorno de B.I.C. delimitado de acuerdo con la resolución de fecha 20/10/1997 publicada en el DOGV $\mathrm{n}^{\circ} 3118$ de fecha 10/11/1997.
Se sitúa además en el interior de la delimitación del Paraje Natural del Desierto de las Palmas. El espacio es paisajísticamente un elemento de referencia de alcance natural y etnográfico al ser parte indisoluble de la conciencia identitaria de la ciudad por su vinculación con los referentes ciudadanos comunitarios como son la Ermita de la Magdalena y los orígenes fundacionales de la ciudad medieval, que se celebran anualmente siguiendo unos festejos ritualizados en el pasado siglo XX. 


\section{Análisis histórico}

La ocupación humana de la zona de la Magdalena se inicia probablemente durante el Neolítico. Es posible que en la última fase de este período, durante el Bronce Final, se ocupara por primera vez el cerro de la Magdalena.

La ocupación estable del sitio se produce en época ibérica, de la cual solo se conserva algún muro descubierto en las recientes excavaciones. Por las características del lugar y la importancia de los restos encontrados, el yacimiento ibérico debió ocupar la zona más elevada donde se encuentra el primer recinto del castillo. En los siglos II-I a.C., con el inicio de la romanización, el viejo oppidum ibérico debió abandonarse.

Durante la época romana hay indicios que permiten suponer la existencia de un asentamiento en las proximidades de la montaña. Tras esta época, no disponemos de ningún hallazgo hasta la presencia cristiana a finales del siglo XI, cuando el castillo permanece ocupado por los aragoneses durante un período de al menos cuatro años, lo que demuestra su existencia previa.

Por otro lado, la vecina ciudad de Borriana, fundada en el siglo IX, comienza a lograr protagonismo durante los siglos XI-XII, cuando se intensifica la amenaza cristiana. El primitivo castell debe relacionarse forzosamente con esta ciudad, como así lo expresan algunas documentos posteriores a la conquista cristiana cuando hablan del Castellón de Burriana, que desempeñaría un coordinado papel de control de la Plana.

Las características de esta primera fortificación nos son desconocidas, pero parece probable que se tratara de una fortificación de pequeñas proporciones. La existencia de una construcción medieval anterior a la actual ha sido posible documentarla arqueológicamente durante los trabajos en el castell, por los fragmentos de mortero reaprovechado y la cerámica de época anterior presentes en el interior de las tapias.

En época almohade, a partir del segundo cuarto del siglo XII, la administración andalusí puso en marcha una política de construcciones militares. Bajo el gobierno de Ibn Mardanîsh (1145-1171), "el rey Lobo" de las crónicas cristianas, los ejércitos catalanes se apoderan de Tortosa, situando la frontera en el río Sénia. En este contexto los castillos de la zona comienzan a ser objeto de donaciones: la primera es la del castrum et villam de Khadrel en 1178 a la Catedral de Tortosa, pero seguirán otros

En conclusión, la construcción del castillo en su forma actual debió realizarse entre el segundo cuarto del siglo XII y el primero del XIII. Posteriormente algunas reformas en el interior de sin afectar de manera sustancial al conjunto.

\section{Intervenciones modernas}

La primera noticia de intervenciones modernas en el recinto del Castell es de J. A. Ceán (1832), quien, cita 'la realización de excavaciones al Castell de la Magdalena. J.A. Balbás (1892) cita estos hallazgos y les añade otros.

Con posterioridad se realiza el primer proyecto de acondicionamiento del conjunto, construyendo unos itinerarios de piedra que faciliten el tránsito por su interior, realizando voladuras con dinamita. Pudiera ser que se tratara de las obras citadas por F. Esteve, dirigidas por el arquitecto F. Tomas Traver, en el curso de las cuales se localizó el tesorillo de monedas andalusíes.

A principios de siglo se inician las plantaciones de pinos procedentes del pinar del Grau. Entre 1950 y 1952 se desarrollan trabajos regulares de excavación de los que no tenemos memorias ni publicaciones que recojan resultados.

En 1977 y 1978, un equipo arqueológico dirigido por A. Bazzana, profesor de la Universidad de Lyon II, realizó sendas campañas de excavaciones de cuyos resultados se han publicado sólo una breve memoria y algunas noticias. De la segunda campaña, realizada en julio de 1978, solo se publicó unas notas breves en una reducida memoria sobre las actividades de su equipo por tierras de Castellón.

En el año 1988 la caótica situación de algunas fortificaciones se denuncia en prensa. Se realizan obras de emergencia y en 1990 se encarga a los arquitectos F. Grande y I. Gil-Mascarell un levantamiento global del conjunto. 


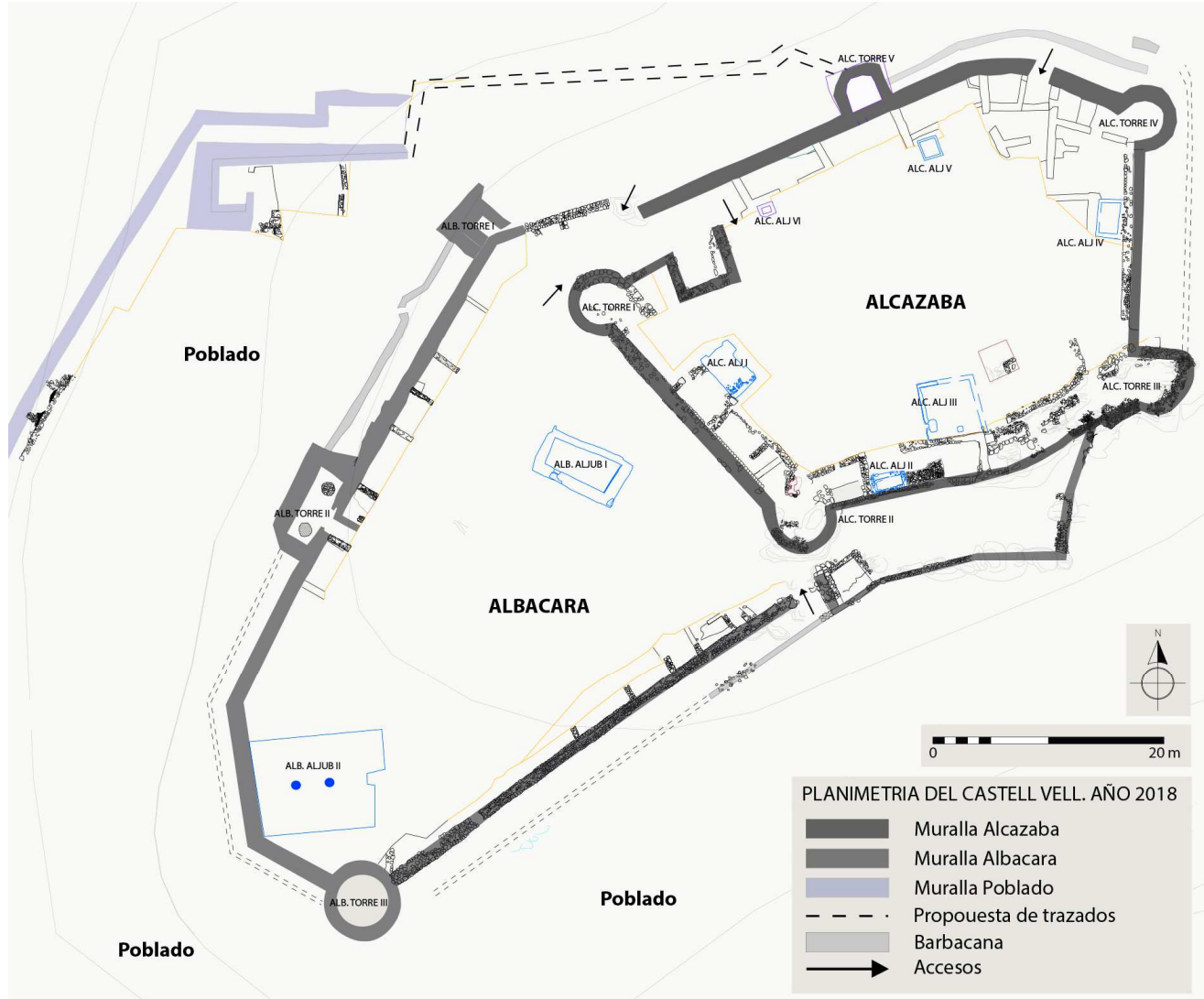

Fig. 1. Planta del Conjunto identificando los diferentes recintos después de la intervención de 2018 (Doc. F.O. 2019).

En el año 1997, el ayuntamiento inicia tareas de excavación arqueológica. En 1999 la Consellería de Cultura encarga al arquitecto I. Gil-Mascarell la redacción del Plan Director de Restauración del Castell, aprobado en 2004.

\section{Descripción}

El Castell Vell (oeste de la Magdalena) está estructurado en tres recintos que se extienden desde la parte más alta de la montaña hacia la vertiente oeste-suroeste, que desciende suavemente formando dos terrazas escalonada. Aparte de las estructuras defensivas existe un hecho incuestionable: la existencia de una pequeña población por la vertiente meridional de la montaña. Esta división en tres partes es característica de los núcleos importantes, con una verdadera madina o ciudad y su ciudadela fortificada o alcazaba, pero aparece también en algunos casti- llos de menor entidad, como es el caso. Analicemos separadamente cada uno de estos recintos.

La Alcazaba. Se encuentra situada en la parte más elevada del castillo, siendo el lugar desde donde el al-qaid administraba el distrito castral y tenía su residencia. Es de planta cuadrangular con una superficie aproximada de $1300 \mathrm{~m}^{2}$ delimitada por una potente muralla dotada de bestorres circulares en las esquinas, a las que hay que añadir una torre poligonal adosada a la muralla norte y una barbacana perimetral externa que flanquea todos los frentes de la alcazaba a excepción del sureste, donde se encuentra la albacara.

La alcazaba contaba con dos accesos. El principal se situaba en el extremo suroeste de la muralla norte, protegido por la torre noroeste de la 
alcazaba. Se trataba de un acceso en codo que comunicaba la alcazaba con la vertiente norte del poblado. Por su parte, el segundo acceso era una poterna secundaria abierta en la muralla norte, cerca de la torre noreste, que actuaría como puerta de servicio comunicando la alcazaba con el valle natural de la Sang dels Moros a través de un camino descendente en zigzag.

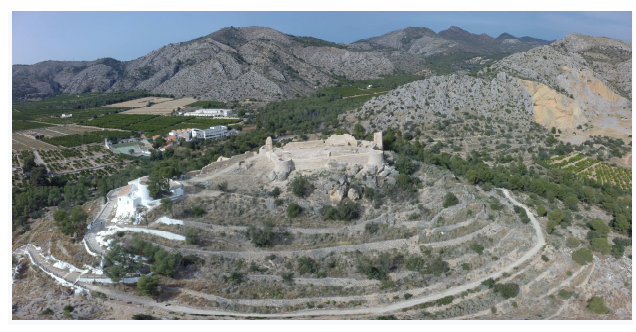

Fig. 2. Vista general del Castell Vell antes de la intervención de 2018 e inserción paisajista en las montañas del Desert (Vuelo, Autor, 2017).

En el interior de la alcazaba únicamente se han realizado excavaciones arqueológicas en los espacios anexos a las murallas. Pese a ello se pueden observar dos áreas bien diferenciadas por los restos constructivos conservados:

- El frente noroeste, donde se encuentra un conjunto de tres recintos rectangulares adosados a la muralla interpretados como almacenes y un pequeño recinto cuadrangular junto a la poterna de $6,5 \mathrm{~m}^{2}$ que ha sido interpretado como un cuerpo de guardia para el control del acceso.

- Los frentes este y sureste, donde las excavaciones arqueológicas realizadas han identificado diversos espacios domésticos que se han podido relacionar con tres casas andalusís de patio central. Los materiales cerámicos provenientes de las excavaciones realizadas en la vivienda permiten fecharlas entre la segunda mitad del siglo XII y el primer tercio del siglo XIII, coincidiendo con el momento anterior a la conquista cristiana. Además del aljibe perteneciente a una de las viviendas, se han contabilizado cinco más en la alcazaba. Todos disponían de potentes muros perimetrales de mampostería encofrada para soportar la presión del agua almacenada y de un grueso revoque interno de mortero de cal para garantizar su impermeabilidad.
La Albacara. Siguiendo el modelo tipológico, se sitúa a los pies de la alcazaba, en la ladera sur de la colina. Su morfología es triangular, con una superficie aproximada de $1400 \mathrm{~m}^{2}$. Estaba delimitada por dos lienzos de muralla cerrando los laterales noroeste y sureste. La muralla noroeste conserva una longitud superior a los $45 \mathrm{~m}$.

Discurre desde la puerta noreste de la propia alcazaba hasta la ermita de la Magdalena. En su trazado disponía de dos torres y una barbacana extramuros. La torre norte estaría relacionada con el control del acceso a la alcazaba desde el poblado. La segunda torre, situada $20 \mathrm{~m}$ al suroeste, es la única de planta rectangular de todas las documentadas en el castillo y, con anterioridad a la conquista cristiana, fue reformada mediante la construcción de un corredor de acceso.

Por su parte la muralla sureste tenía un recorrido lineal de $42 \mathrm{~m}$ comunicando la actual torrecampanario de la ermita con la puerta de acceso a la albacara desde el poblado, defendida por la torre suroeste de la alcazaba. El único elemento defensivo destacado de este frente era la propia torre-campanario de la ermita, situada en su extremo suroeste. Se trata de una torre circular de características similares a las documentadas en la alcazaba y que aún conserva un pequeño postigo en forma de arco de herradura. Finalmente, el cerramiento de la albacara se completaba con el tramo de muralla que unía los dos anteriores y que actualmente conforma la fachada del ermitorio y la pared posterior del patio de la hospedería.

El único acceso documentado a la albacara se situaba en el extremo noreste de la muralla sureste. Era un acceso en codo que comunicaba con el poblado a través de la liza de este último. De los trabajos realizados se ha demostrado la existencia de otro en el punto de tangencia con la alcazaba.

De las estructuras conservadas en el interior de la albacara destacan los dos aljibes conservados. El menor $\left(32 \mathrm{~m}^{2}\right)$ ocupa una posición central y tal vez formase parte de una estructura de mayores dimensiones que no se ha conservado.

El segundo aljibe $\left(100 \mathrm{~m}^{2}\right)$ es el más grande de los documentados en el castillo. Se encuentra 
adosado al tramo de muralla oeste de la albacara $\mathrm{y}$, desde el siglo $\mathrm{XV}$, alberga en su interior la ermita de Santa María Magdalena. Gracias a su uso, más o menos continuado desde la Edad Media, se ha conservado la estructura original del aljibe sin grandes alteraciones, formada por dos naves paralelas cubiertas por bóvedas de cañón y comunicadas por tres arcos de herradura. Se trata de uno de los pocos ejemplos de aljibes dobles andalusís existentes en nuestras comarcas, similar al documentado en el Castell de Nules.

Otras estructuras remarcables de la albacara son los almacenes que se encuentran adosados a las murallas noroeste y sureste. Hasta el momento se han identificado 15 de estas estancias, todas ellas rectangulares y similares a las documentadas junto a la muralla noroeste de la alcazaba.

El Poblado. El poblado es el espacio más desconocido del Castillo, pese a que en él residiría la mayor parte de la población. En este recinto se ubicarían elementos tan destacados como la mezquita (masyid), los baños (hamman) o el zoco $(s \bar{u} q)$. Los pocos datos referentes al mismo se limitan a un plano publicado por J. B. Porcar en 1931 y al resultado de las excavaciones arqueológicas efectuadas entorno a su torre norte en el año 2010.

Gracias al plano de Porcar podemos intuir que el poblado se extendía en forma de media luna por las laderas sur y este de la colina y tenía una superficie aproximada de $10000 \mathrm{~m}^{2}$.

También que su urbanismo era irregular, con las viviendas asentadas en terrazas adaptadas a las curvas de nivel. Según el plano, el poblado estaba amurallado y contaba con un acceso principal al sureste y dos poternas secundarias abiertas al norte y noreste de la muralla que todavía no han sido localizadas a día de hoy.

En general, las estructuras defensivas estudiadas presentan una gran homogeneidad en cuanto a técnicas constructivas. La estructura básica son los muros escalonados construidos con tapia. La parte baja utiliza mampuestos calizos de grandes dimensiones y se coloca como zócalo protector de la tapia de tierra crostada, construida sobre ella. El uso combinado de la mampostería y de la tapia de tierra no prefigura la existencia de momentos constructivos diferentes, ya que aparecen utilizadas conjuntamente en elementos claramente coetáneos de la fortificación.

Esta combinación de técnicas, por otra parte bastante corriente en los castillos musulmanes valencianos, es general por toda la fortificación, alternándose en ocasiones de manera irregular. La tapia es del tipo "de tierra costrada" y, en general, están bien paramentadas, aunque en algún caso no están ajustadas perfectamente, dejando cejas o costurones en las juntas de unión.

En cuanto a las torres, las de planta circular aparecen tanto en el primero como en el segundo recinto, por lo que no pueden considerarse anteriores. Sin embargo, resulta evidente que al menos la torre norte del primer recinto y la norte del segundo recinto están adosadas, identificándose con ellas una segunda fase constructiva, sin que pueda concretarse si se trata de una ampliación-reforzamiento de la fortificación muy posterior en el tiempo a la finalización de las murallas respectivas, o son inmediatamente posteriores al muro y formando parte de un mismo proyecto constructivo.

En la arquitectura militar almohade encontramos ejemplos paralelos a una de estas torres, concretamente la $\mathrm{N}$ del primer recinto, que presenta un facetado heptagonal. En la muralla almohade de Sevilla encontramos algún caso de torre parecida (Torres Balbás, s. A., 508, 571). Este hecho, junto con la utilización generalizada de la tapia por toda la fortificación, apoya una datación tardía, entre los siglos XII y XIII, del castillo de la Magdalena.

En cuanto al estudio metrológico, los tamaños documentados son en general bastante heterogéneos. Las alturas de las cajas de tapia suelen tener $82 \mathrm{~cm}$ mientras que el ancho de las murallas oscila entre 110 y $165 \mathrm{~cm}$. Los muros interiores menores tienen $47 \mathrm{~cm}$. Se comprueba como en la construcción del Castell Vell se combinan los dos principales sistemas andalusíes: el codo rassasí de $55 \mathrm{~cm}$ y el codo mamuní de 47 . 


\section{Análisis patológico}

La baja calidad de los materiales constructivos de los muros y de la falta de mantenimiento derivan la mayor parte de los daños que sufre. El agente agresivo básico en este tipo de construcción es el agua.

Los puntos o zonas básicas de ataque y erosión del muro son tres: la parte superior de los muros, que una vez perdido su revestimiento o protección propia se va deteriorando al disolver el agua las partículas, con su posterior arrastre y la erosión subsiguiente.

En segundo lugar, los paramentos, que sufren la acción del agua y el viento al actuar conjuntamente y transportar sales marinas en disolución, ejerciendo una labor abrasiva.

El tercer punto básico de agresión es la base de asiento de los muros que sufren la acción de la humedad ascendente, con la consiguiente pérdida de resistencia. La presión del agua cuando ejercen la función de contención de tierras en grandes desniveles sin existir un sistema eficiente de canalización de las aguas de lluvia.

Otro motivo de deterioro es la biodegradación por medio de la acción de las plantas y animales. En menor medida son también agentes destructores las algas, líquenes y los pájaros, por la acción de los excrementos y formación de nidos.

\section{La intervención del año 2018: descripción de la fase $V$}

Parte 1. Castell. En desarrollo del Plan Director, se plantea una intervención de "consolidación de restos" y recomposición esencial del carácter de "recinto" sin pretender en lo más mínimo una reconstrucción aventurada de una construcción de la que no se poseen datos. Las actividades que se han desarrollado han sido las siguientes:

\section{1/ ALCAZABA (Primer Recinto)}

A. Colocación de una puerta en la poterna norte.

B. Recrecido del muro Este.
C. Excavación arqueológica completa del ala norte de la Alcazaba. Consolidación de hallazgos.

D. Reposición de portón de acceso.

2/ ALBACAR (Segundo Recinto)

E. Excavación arqueológica

F. Recomposición del muro norte

G. Puerta al $2^{\circ}$ recinto para acceso de material

H. Recomposición del muro sur

\section{3/ RECORRIDO DIDÁCTICO}

Definición de un itinerario didáctico delimitado con medios poco invasivos.

Parte 2. Centro de Interpretación (C.I.). En un plano topográfico de finales del siglo $\mathrm{XX}$, se señala una construcción preexistente En este punto existían signos inequívocos de una ocupación antrópica del medio.

Posicionar en este punto el CI es una actitud muy respetuosa. Es un método muy empleado en la antiguiedad, cuando una construcción se levantaba sobre otra, intentando aprovechar el material preexistente. Es una prueba de sostenibilidad, pero sobre todo es una restauración de un paisaje; la presencia de un volumen en este punto no es una distorsión.

Se concluyó que era el lugar preciso para el CI. Minimiza impacto porque es difícilmente visible desde la carretera. Restituye un volumen que forma parte de la memoria del lugar. Plantea la posibilidad de "reutilizar" partes construidas sin ningún valor arqueológico y permite aprovechar al máximo el valor del territorio.

Los trabajos que se realizaron verificaron, además, la existencia de una alquería de inicios del XIX que contenía debajo un interesante asentamiento musulmán, muy arcaico, en uno de los extremos. Para dignificar el entorno se va a plantear un sistema de accesos conformado mediante muros de mampostería que conecten la posición de la fututa edificación con una construcción de recogida de agua (Aljub) que se sitúa en las inmediaciones. El edificio tiene una superficie útil de $125,12 \mathrm{~m}^{2}$ y una construida de $154,60 \mathrm{~m}^{2}$. La idea arquitectónica del CI pretende unificar dos ámbitos dialécticamente activos en el mundo de la arquitectura reciente desde la celebración de VII Congreso CIAM en Bérgamo 
cuando se contraponen las tradiciones vernácula y moderna en el deseo de alcanzar una condición artística para la Arquitectura Moderna.

Referentes de la arquitectura vernácula. La referencia respecto de la arquitectura vernácula se dirige hacia las denominadas casetes de volta, una construcción intemporal que pertenece a la koiné mediterránea, empleada por toda la ribera de este mar con multitud de usos y técnicas de conformación.

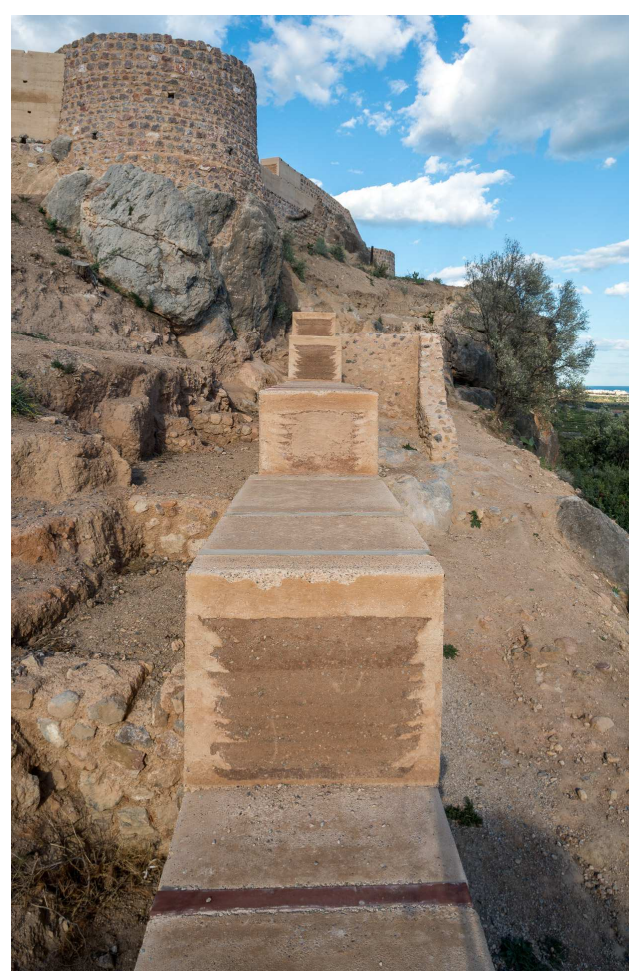

Fig. 3. Fábricas de tapial de tierra calicostrada en consolidación de muro existente (Autor, 2017).

Esta condición abstracta y previa a cualquier consideración formal o funcional convierten a este tipo constructivo en un elemento que posibilita su empleo sin ningún tipo de condición previa y desvinculándolo de toda concesión. Es un tipo de construcción sincera que adquiere su personalidad a partir de asumir la naturaleza tectónica de su conformación.

Es además una construcción intemporal cuyos orígenes puede que se pierdan en los albores del neolítico. Esta "no condición” funcional y "no adscripción" a movimiento formal alguno es lo que legitima la adopción del tipo como un referente posible de cara a asumir libremente la relación con una condición vernácula para el nuevo asentamiento.

La multiplicidad y la diafanidad del espacio interior obtenido hacen plausible la adopción e introducción de usos diferentes y diversos de los que inicialmente podría pensarse que formarían parte de los posibles en el interior de este contenedor transcultural. Pero es que esta misma técnica y este mismo método constructivo se encuentra presente en el Castell Vell. Si observamos los elementos conservados en su interior que se corresponden a antiguos aljibes o almacenes de granos podemos ver que responden a este mismo planteamiento.

Es tan "usual" este sistema que se ha empleado en multitud de partes del complejo del castillo. Y se da el caso que han sido las estructuras que más han pervivido.

Referentes de arquitectura moderna. La lectura a partir de la Arquitectura moderna del siglo XX debe comenzar con las apuestas de racionalismo lecorbusierano, por más que formalmente, la asimilación de una envolvente abovedada fuera utilizada por el ala más primeriza de la modernidad en sus edificios manifiesto (Caso de Adolf Loos en su Villa Stein).

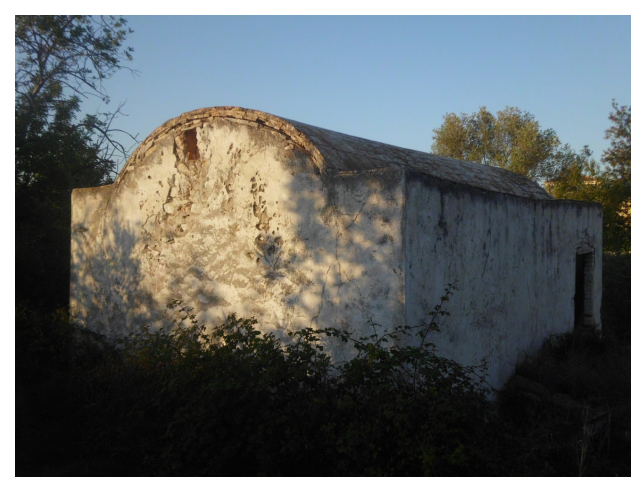

Fig. 4. Caseta de volta existente. Provincia de Castellón (Autor, 2018).

Cuando el maestro suizo, en el centro de París, apuesta por valorar la tradición constructiva que 
había observado en sus viajes por Italia y Grecia introduce en el discurso moderno la necesidad de este dialogo permanente entre tradición y nuevas técnicas y concepciones del espacio del tiempo post-relativista. El trabajo de Le Corbusier en la Maison Jaoul inicia todo un discurso lingüístico en la arquitectura moderna que, por primera vez, no parte de lo nuevo sino que reivindica la técnica de lo cotidiano, asumiendo incluso las limitaciones que le impiden estar seguro de sus propios logros tecnológicos.

Solución del Centro de Interpretación. La solución arquitectónica del C. I. parte pues de la observación de la construcción precedente, una construcción longitudinal dispuesta en sentido norte-sur. Esta condición alargada queda asimilada a la disposición de una caseta de volta que actuará dividida, permitiendo, mediante una abertura, disfrutar de los vientos dominantes en sentido este-oeste. Queda pues determinada la geometría de la planta que, si se asimila tectónicamente al muro portante, obtendremos un rectángulo perfecto. El rectángulo, al ser vulnerado por su parte central se convierte en dos piezas en forma de $\mathrm{C}$ de tamaño diverso. Tan solo precisamos de la componente funcional para poder interpretar esta unidad como dos partes de un todo. Una pasa a contener los espacios servidores y otra a sume la condición preferente de espacio servido.

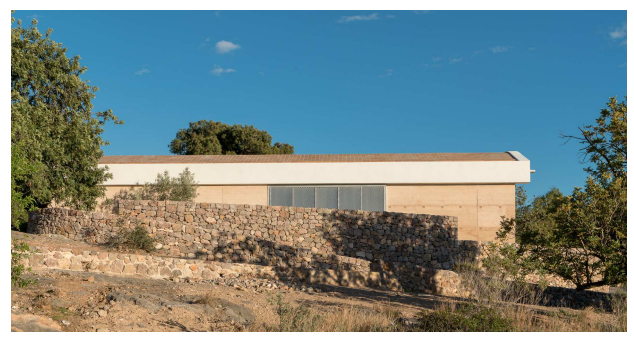

Fig. 5. Lateral del Centro de Interpretación (J. Roig, 2018).

Así pues, el C.I. es un organismo unitario, de planta rectangular, dividido por un generoso espacio abierto a modo de veranda, que se cubre por una bóveda rebajada. Su localización en el territorio se produce aprovechando la edificación preexistente de manera que la veranda sea un punto desde donde observar al mismo tiempo el espacio de llegada y la visión lejana del Mediterráneo. Todo gravita respecto de este espacio central cubierto. En la zona de los componentes "servidos" las dos salas se disponen en paralelo, de manera que un tabique móvil retráctil puede integrarlas. Entre ellas se sitúa el despacho del vigilante. En el otro extremo de la veranda dos aseos y un almacén poseen acceso independiente desde ella. Este espacio protegido del sol y la lluvia funcionará abierto. Si bien existen dos puertas correderas que permiten que pase a tener la condición de espacio cerrado; total o parcialmente ya, en los meses de invierno es conveniente cortar la corriente de aire permanente. Estas compuertas funcionan con una doble capa, una exterior antivandálica (metal estirado) y una interior de policarbonato celular traslúcido.

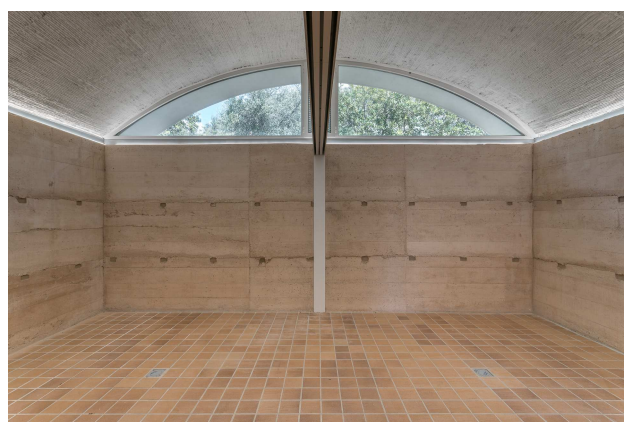

Fig. 6. Vista interior de las salas con el muro móvil en el centro (J. Roig, 2018).

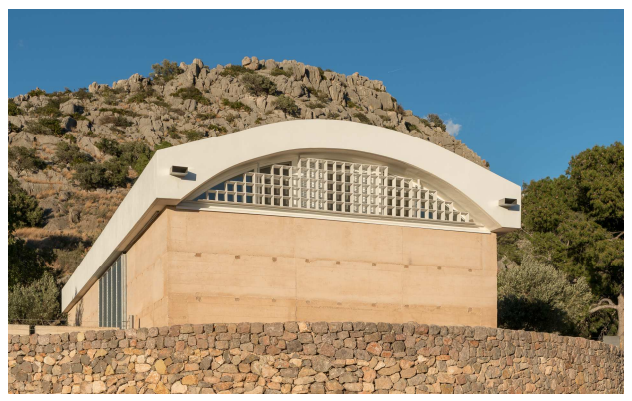

Fig. 7. Testero oeste con celosía cerámica (J Roig, 2018).

La condición material del espacio resulta de asumir decididamente la condición portante de los muros de cierre. Son muros de una hoja, de hormigón de cal ejecutados con la técnica de la TAPIA, la misma utilizada en los lienzos del 
Castell Vell, y empleando dos anchos diferentes. Se busca con ello "mostrar" la técnica que ha permitido la recomposición de las partes dañadas del monumento en el mismo punto de acogida de sus visitantes. Todas las paredes de las salas se resuelven con esta técnica de tapial calicostrado de tierra, que cuenta además con excelentes prestaciones acústicas.

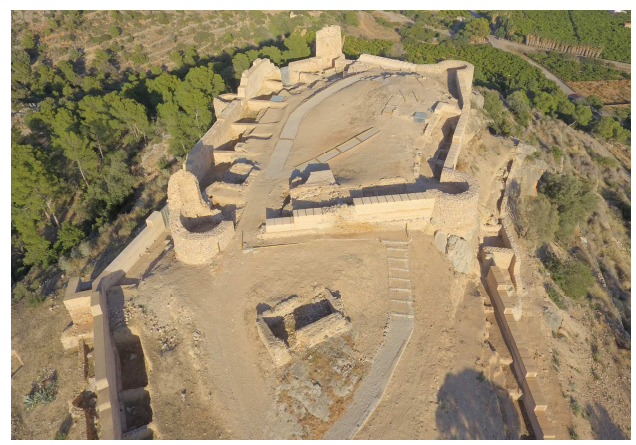

Fig. 8. Vista final después de la intervención. Se observa el circuito de visita que aprovecha estructuras de intervenciones anteriores (Autor, 2018).

La cubierta se resuelve mediante sobre un forjado de hormigón armado visto. Este es una bóveda rebajada conformada con losa de $30 \mathrm{~cm}$ de espesor que se encofra inferiormente con cañas a la manera de los alarifes mudéjares. El posicionamiento de una luz artificial rasante mejora la percepción de esta textura natural que busca dotar de calidez al interior, mejorando, al mismo tiempo, su componente acústica. Los acabados interiores de los espacios de servicios son los que corresponden con unos elementos higiénicos: cerámica en paredes y particiones de panel fenólico. Los pavimentos son de gres cerámico de extrusión en pequeño formato $\left(\begin{array}{lll}10 & \mathrm{x} & 10\end{array}\right)$ colocado en junta gruesa.

\section{Notas}

En el proyecto Básico y de Ejecución del que es deudor la presente comunicación también intervinieron como colaboradores los siguientes técnicos:

D. Juan Francisco Cabedo Martí, Arquitecto. Dña. Vicenta Marta Llombart Prior, Arquitecta.

D. Ferrán Arasa Gil, Historiador.

D. Miguel Masip Piqueras, Topógrafo.

D. Adrián Chiva Hernández, Arquitecto Técnico de Cyrespa Arquitectónico S.L.

También intervino en apoyo al equipo D. Ignacio Gil-Mascarell Boscá Arquitecto Asesor.

\section{Bibliography}

Balbás, J.A. (1982). El libro de la provincia de Castellón, Imp. Armengot, Castellón.

Ceán Bermúdez, J.A. (1832). Sumario de las antigüedades romanas que hay en España: en especial las pertenecientes á las Bellas Artes, Impr. de M. de Burgos.

Torres Balbas, L. (1955). Artes almoravide y almohade, Instituto Diego Velázquez, Madrid. 
